\title{
REPRESENTAÇÕES DE GÊNERO, SEXUALIDADE E CORPO NA MÍDIA
}

\author{
Representations of gender, sexuality and
} body on the media

Jane Felipe*

\section{Resumo}

O presente artigo pretende analisar as representações de gênero, sexualidade e corpo veiculadas pela mídia impressa e televisiva, a partir dos Estudos Feministas e dos Estudos Culturais, na perspectiva pós-estruturalista de análise. Trata-se, portanto, de discutir tais conceitos como construções sociais e históricas, analisando o papel da mídia brasileira na subjetivação dos corpos infanto-juvenis, especialmente no que diz respeito à erotização.

Palavras-chave: gênero, sexualidade, mídia.

\section{Abstract}

The main objective of the present article is to analyze representations of gender, sexuality and body propagated by the printed media and television from the theoretical and methodological reference in the Cultural Studies and Female Studies, especially brands associated with post-structuralist approach. This article also intends to argue how these concepts, understood as social and historical constructions, analyzing the paper of the Brazilian

* Mestre em Educação pela Universidade Federal Fluminense - RJ e doutora em Educação pela Universidade Federal do rio Grande do Sul UFRGS. Professora do Departamento de Estudos Especializados da Faculdade de Educação da UFRGS e coordenadora do GEERGE - Grupo de Estudos de Educação e Relações de Gênero, vinculado ao PPGEDU/FACED/UFRGS.

(nana_felipe@yahoo.com.br) 
media in the subjectivation of the children's and youthful's bodies, especially about erotization.

Keywords: gender, sexuality, media

O presente artigo pretende analisar as representações de gênero, sexualidade e corpo veiculadas pela mídia impressa e televisiva, a partir dos Estudos Feministas e dos Estudos Culturais, na perspectiva pósestruturalista de análise. Trata-se, portanto, de discutir tais conceitos como construções sociais e históricas, analisando o papel da mídia brasileira na subjetivação dos corpos infanto-juvenis, especialmente no que diz respeito à erotização. Pretendo ainda discutir o processo de 'pedofilização' como prática social contemporânea, bem como compartilhar algumas pesquisas desenvolvidas sobre essa temática no campo da educação.

\section{ESPECIFICANDO O CAMPO CONCEITUAL}

Os Estudos Culturais concebem a cultura como um campo de luta e contestação por meio do qual os indivíduos que formam os diversos grupos sociais, cada qual com suas peculiaridades e singularidades, vão se constituindo e produzindo sentidos.

Atualmente, é possível verificar que as pesquisas desenvolvidas no campo dos Estudos Culturais se apresentam bastante diversificadas e múltiplas questões têm sido abordadas: desde aquelas que dizem respeito às práticas escolares e pedagógicas propriamente ditas, até as que se voltam para a discussão acerca das produções desenvolvidas em outras instâncias culturais como é o caso de programas de rádio e televisão, propagandas, filmes, novelas, jornais, revistas, entre tantas outras que poderiam ser mencionadas.

Os Estudos Feministas, por sua vez, trouxeram para o âmbito acadêmico a discussão de temas antes tidos como secundários, tais como família, sexualidade e trabalho doméstico, até então considerados 
pouco importantes no cenário teórico (MEYER, 2003b). Além disso, estudiosas feministas (SCOTT, 1995; LOURO, 1997, 1999, 2004) têm procurado compreender gênero como uma categoria relacional. Sendo assim, os estudos e as pesquisas recentes em torno dessa temática procuram articulá-la com outras categorias tais como geração, raça, etnia, classe social, entre outras. Cabe ressaltar que a abordagem pósestruturalista possui um caráter bastante produtivo para as pesquisas que lidam com essas categorias, trazendo a possibilidade de discutir as relações de poder existentes na sociedade. $\mathrm{Na}$ análise pós-estruturalista não há o intuito de "procurar" e "descobrir" verdades fundantes que poderiam estar escondidas em algum lugar ${ }^{1}$. Tal processo, por sua vez, remete ao conceito de representação, que reúne tanto práticas de significação lingüística e cultural como sistemas simbólicos por meio dos quais os significados podem ser construídos. Tais significados, por exemplo, auxiliam meninos e meninas a compreenderem as experiências vivenciadas e, a partir daí, escolherem o que devem ser e fazer, delineando assim suas identidades (MEYER, 2003b).

Cabe, portanto, destacar que o conceito de identidade deve aqui ser tomado algo impresso pela cultura, na medida em que as identidades são nomeadas a partir de um determinado contexto, e de expectativas que se criam em torno delas, como por exemplo ser homem ou mulher, ser homo ou heterossexual.

Desta forma, é possível afirmar que nossas identidades são constituídas culturalmente e estão fortemente vinculadas às práticas sociais. Para Stuart Hall (1997, p. 33) toda prática social depende e tem relação com o significado: "consequentemente, a cultura é uma das condições constitutivas de existência dessa prática, que toda prática social tem uma dimensão cultural" e ainda, que ela tem um caráter discursivo.

Em relação à infância, a construção das identidades articula-se aos discursos a respeito da criança que são veiculados e sustentados por diversos artefatos culturais. Dentre tais artefatos, a mídia vem ocupando

1 Para um maior aprofundamento de tais questões ver, por exemplo, Cheek (2000). 
lugar de destaque nos últimos tempos, na medida em que veicula uma gama enorme de informações sobre os mais variados assuntos. Tais informações mostram desde modos de ser criança até do que devem gostar e como devem proceder.

Shirley Steinberg e Joe Kincheloe (2001, p. 14) argumentam que existem novas áreas de aprendizado que podem ser chamadas de Pedagogias Culturais. Tais pedagogias incluem a escola, mas vão além dela, abrangendo uma variedade de locais, "onde o poder é organizado e difundido, incluindose bibliotecas, TVs, cinemas, jornais, revistas, brinquedos, propagandas, videogames, livros, esportes, etc."

\section{MÍDIA E PRODUÇÃO DE CONHECIMENTO}

A velocidade com que surgem novas tecnologias têm possibilitado a emergência de outras instituições culturais que, de uma forma ou de outra, acabam por educar e auxiliar na construção de identidades de meninos e meninas, jovens e adultos. Neste sentido, a mídia se tornou, nas últimas décadas, uma poderosa instância de produção do conhecimento. Como afirma Rosa Fischer (1999, p. 18)

Se considerarmos que a mídia, hoje, é responsável por um imenso volume de trocas simbólicas e materiais em dimensões globais, abre-se para a educação um novo conjunto de problemas, numa dinâmica social que exige não só medidas urgentes por parte das políticas públicas educacionais, mas igualmente uma reflexão mais acurada sobre as relações entre educação e cultura (...).

Os discursos veiculados pela mídia acionam poderosos efeitos de verdade, que podem contribuir significativamente para a construção das identidades dos sujeitos. Neste sentido, podemos afirmar que a mídia, especialmente a televisiva, pode ser considerada como um espaço educativo, uma vez que produz conhecimentos a respeito da vida, do mundo que nos cerca, de como devemos ser ou nos comportar, do que devemos gostar. 
Rosa Fischer (2001 , p. 18) argumenta ainda que a televisão contribui decisivamente na constituição e formação dos sujeitos contemporâneos. Ela chama a atenção para o fato de que a “(...) a presença da TV na vida cotidiana tem importantes repercussões nas práticas escolares, na medida em que crianças, jovens e adultos de todas as camadas sociais empreendem modos de ser e estar no mundo também nesse espaço da cultura”.

Bianca Guizzo (2005), em sua dissertação de mestrado, menciona a pesquisa feita por um canal de TV à cabo ${ }^{2}$, mostrando que $81 \%$ das crianças entrevistadas assistem à televisão mais de 3 horas por dia. Sobre tal fascínio das crianças pela TV, Steinberg e Kincheloe (2001, p. 42) ressaltam que a cultura infantil tem, muitas vezes, de providenciar uma fuga bem-vinda de tão dura realidade - não é de surpreender que o tempo gasto assistindo TV seja tão longo entre as crianças pobres e sem posses.

Associado à televisão há outras tecnologias (como videogames, por exemplo), que são dominadas com muita competência pelas crianças e adolescentes. Tais artefatos culturais - com destaque especial para a televisão - apresentam-se como importantíssimos instrumentos de formação, principalmente das novas gerações (GUIZZO, 2005).

Importante mencionar que, em seus primórdios - década de 50 do século XX - a televisão brasileira veiculava, fundamentalmente, programas destinados aos adultos. Programas infantis que se baseavam nos clássicos da literatura universal (Cinderela, Chapeuzinho Vermelho, Os Três Porquinhos, entre outros) foram os primeiros a incluir a criança como espectadora no mundo televisivo (PEREIRA, 2002).

Nos anos 60, as crianças deixaram de ser meras espectadoras e passaram a ser também protagonistas de algumas programações transmitidas pela TV, especialmente como personagem de espetáculos artísticos e culturais.

Já na década de 80, a inclusão das crianças na mídia sofreu algumas alterações, pois programas como o Xou da Xuxa (transmitido

2 Trata-se de pesquisa desenvolvida pela Cartoon Network, canal de TV a cabo destinado ao público infanto-juvenil. A pesquisa foi feita com 1503 meninas e meninos de 6 a 11 anos das classes A, B e C de São Paulo, Rio de Janeiro, Curitiba e Belo Horizonte (VEIGA, 2003). Ver reportagem divulgada na Revista Época, em 03 de novembro de 2003. 
pela TV Globo de 1986 a 1995) promoviam gincanas e brincadeiras com a participação dos "baixinhos". No âmbito desses programas, havia também a exibição de variados produtos infantis. A partir daí, no intervalo de programas desse tipo, as propagandas televisivas infantis passaram a ganhar maior destaque. Em tais propagandas as crianças eram interpeladas a comprar desde guloseimas (bolachas recheadas, chocolates, etc.) até roupas e acessórios que levavam o nome de apresentadoras desses programas infantis (Xuxa, Angélica e Mara Maravilha) ou dos personagens protagonistas (He-man, por exemplo) dos desenhos animados transmitidos durante a programação de tais programas. Conforme destacam Steinberg e Kincheloe (2001, p. 24; 2004), “corporações que fazem propagandas de toda a parafernália para crianças consumirem promovem uma teologia de consumo que efetivamente promete redenção e felicidade através do ato de consumo" (grifos dos autores).

Vale lembrar que de algumas décadas para cá, especialmente a partir da década de 50 do século XX, as crianças passaram a ocupar um lugar de visibilidade, inclusive sendo potencializadas como ávidas consumidoras (STEINBERG, 1997, 2001; BUCKINGHAM, 2002). Conforme ressalta Rita Pereira (2002, p. 84),

(...) a criança não é mais colocada como dependente do adulto, seja no âmbito mais amplo da esfera econômicopolítica, seja no plano mais restrito da vida familiar e escolar, mesmo porque o lugar que o mercado concedeu para a criança tem sua história intimamente ligada às transformações das relaçôes entre adultos e crianças. Olhada inicialmente como filho do cliente que se relacionava com o mercado a partir do uso de bens materiais e culturais que se ofereciam a ela à margem da sua opinião, a criança é elevada ao status de cliente, isto é, um sujeito que compra, gasta, consome e, sobretudo, é muito exigente (grifos da autora).

Tal visibilidade que as crianças vêm ganhando nos últimos tempos é fruto de importantes transformações - sociais, culturais, econômicas e 
políticas -, conforme procurei mostrar em trabalhos anteriores (FELIPE, $1999,2000,2002)^{3}$.

Cabe lembrar ainda que embora os anúncios televisivos, e de forma mais abrangente a publicidade, tenham assumido definitivamente as crianças consumidoras, especialmente a partir das décadas de 70 e 80 do século $\mathrm{XX}$, suas imagens, antes disso, já estavam presentes na publicidade. Elas eram visibilizadas em propagandas que ofereciam produtos tipicamente do mundo adulto como, por exemplo, automóveis, sabão em pó, bancos, seguros, etc. (PEREIRA, 2002). Atualmente, além de estarem presentes nas propagandas voltadas que anunciam produtos voltados especificamente a elas - picolés, brinquedos, jogos, filmes, videogames, roupas, calçados, entre outros -, as crianças também aparecem como protagonistas de anúncios voltados para os adultos (bancos, carros, seguros, computadores, etc). Em geral, são representadas como espertas, independentes e capazes (de manipular as tecnologias digitais, por exemplo). É possível afirmar que, em razão da TV ser um dos meios de comunicação mais utilizados pelas crianças, as propagandas televisivas nela veiculadas certamente produzem não só necessidades de consumo, mas acionam formas de subjetivação.

A mídia televisiva tem ocupado, desta forma, um lugar importante na vida não só das crianças, mas também dos adultos, na medida em que ela está presente em grande parte dos lares - ao contrário da Internet, por exemplo, cujo acesso é privilégio apenas de uma minoria privilegiada, em se tratando da realidade brasileira. A televisão, ao mesmo tempo em que é considerada um espaço de diversão, mostra-se também como um poderoso espaço educativo.

\section{SEXUALIDADES EM DISCURSO E CORPOS INFANTIS EROTIZADOS}

As análises advindas das contribuições de Michel Foucault (1989, 1992, 1993) sobre o uso do corpo e seus prazeres ao longo da história,

3 Refiro-me à pesquisa Infância, sexualidade e gênero: a 'pedofilização' da sociedade e o consumo dos corpos infantis, cujo início se deu em agosto de 2002, com término em dezembro de 2004. 
as relações de poder-saber e o governo dos corpos, podem ser muito produtivas para se pensar alguns temas ligados à sexualidade, bem como perceber e analisar como os sujeitos têm sido posicionados pelos diferentes discursos - médico, psicológico, jurídico, religioso e educacional.

A sexualidade, por sua vez, tem sido colocada como central à nossa existência, sendo remetida em geral a um discurso essencialista e universal. No entanto, Jeffrey Weeks (1999) observa que a sexualidade, embora tenha como suporte o corpo biológico, deve ser vista como uma construção social, uma invenção histórica, pois o sentido e a importância a ela atribuída são criadas em situações sociais concretas. A sexualidade remete, portanto, a uma série de crenças, comportamentos, relações e identidades sociais historicamente construídas.

$\mathrm{Na}$ contemporaneidade os corpos podem ser entendidos como possíveis mensageiros, produzidos na pluralidade de culturas e práticas educativas. Segundo Graciema da Rosa (2004, p. 7), o corpo pode ser visto como "um hipertexto, cenário, mapa, sinalizador, território de protesto e de criação. Subterfúgios e dribles ... acessórios, adornos, decorações”.

Embora colocados em discurso de forma tão intensa nas últimas décadas, os corpos têm sido minuciosamente vigiados e controlados, especialmente no que se refere à sexualidade (FELIPE, 2005).

É importante observar o quanto determinados temas diretamente ligados ao exercício do corpo e seus prazeres, tais como violência sexual, pedofilia, estupro, homossexualidade, bissexualidade, permanecem praticamente intocados, em certos casos, quase inquestionáveis. A pedofilia, por exemplo, tem sido associada a uma prática eminentemente masculina, havendo poucos estudos e estatísticas sobre tal comportamento entre mulheres (GREEN, 2001). Os discursos que idealizam e glorificam a mulher-mãe têm dificultado a discussão mais corajosa de entendermos a maternidade também como aprisionamento. Autoras como Elisabeth Badinter (1985), Erica Burman (1999), Aminatta Forna (1999) e Dagmar Meyer (2000) analisam o quanto a suposta completude das mulheres por meio da maternidade tem sido construída historicamente, colocando-as como acima de qualquer suspeita, reforçando assim as concepções de que 
determinados comportamentos sexuais só podem ser praticados apenas por homens, em suas sexualidades "desenfreadas" e "animalescas". Tais conceitos se conectam, portanto, às concepções e expectativas presentes em torno do exercício das masculinidades e feminilidades.

No âmbito escolar ou mesmo nos cursos de formação docente, esses temas são, quase sempre, ignorados. Em geral, quando ocorrem tais discussões em torno da sexualidade, estas se dão a partir de uma matriz biologicista, ou pelo viés da doença, da morte e da moral, principalmente depois do advento da AIDS.

Os resultados de algumas pesquisas têm permitido perceber o quanto as crianças estão sendo subjetivadas na construção de suas identidades de gênero e sexuais por um crescente apelo ao erotismo (GUIZZO, 2005; GUERRA, 2005).

O uso dos corpos infantis, especialmente os corpos femininos, visibilizados como desejáveis, têm sido uma constante na mídia brasileira, seja através da publicidade impressa ou televisiva, seja através de outdoors ou mesmo programas de TV (novelas, minisséries, etc). Esse processo de erotização crescente dos corpos infantis, que venho chamando de 'pedofilização', pode acionar algumas reflexões a respeito da interessante contradição existente nas sociedades contemporâneas, em especial na sociedade brasileira, pois ao mesmo tempo em que se lançam campanhas de combate à pedofilia (UNESCO, 1999; BRASIL, 2004), na tentativa de preservar a integridade física e emocional das crianças, propaga-se, no cenário brasileiro, uma espécie de pedofilia consentida, amplamente aceita e difundida principalmente pelos veículos de comunicação de massa, posicionando os corpos infantis como objetos de desejo e de consumo (WALKERDINE, 1999, FELIPE e GUIZZO, 2003). Em geral, a sociedade nem se dá conta do quanto ela própria está produzindo novas identidades sexuais e de gênero, a partir da objetificação de seus corpos.

A partir da perspectiva da análise cultural, seria interessante aprofundarmos as discussões em torno das representações de criança, infância e sua respectiva educação e de que forma tais representações têm sido veiculadas e objetificadas pela mídia (televisiva e impressa), 
especialmente no que se refere às questões de gênero e sexualidade, bem como seus possíveis efeitos para a formação das identidades infantis. Cabe ainda ressaltar a importância de estabelecermos, no âmbito da formação docente (inicial e continuada), um amplo debate sobre esses temas, levantando subsídios para a elaboração de propostas pedagógicas (como recomenda os Parâmetros Curriculares Nacionais), que levem em consideração a temática de gênero, sexualidade, em seus diversos atravessamentos (classe social, raça, etnia, geração, religião, entre outros). Tais discussões são indispensáveis para pensarmos sobre a grave situação de violência/abuso e exploração sexual infanto-juvenil.

\section{REFERÊNCIAS}

BADINTER, Elisabeth. Um amor conquistado: o mito do amor materno. Rio de Janeiro: Nova Fronteira, 1985.

BRASIL. Guia escolar: métodos para identificação de sinais de abuso e exploração sexual de crianças e adolescentes. Brasília: SNDH/ME, 2004.

BUCKINGHAM, David. Crecer en la era de los medios eletrónicos. Madrid: Morata, 2002.

BURMAN, Erica. La desconstrucción de la psicologia evolutiva. Madrid: Visor, 1998.

CHEEK, Julianne. Postmodern and poststrutucral approaches to nursing research. London: Sage, 2000.

FELIPE, Jane. "Cachorras", "tigrões" e outros "bichos": problematizando gênero e sexualidade no contexto escolar. In: Fazendo escola, v. 02, 2002. p. 26-30.

. Entre tias e tiazinhas: pedagogias culturais em circulação. In: 
SILVA, Luiz Heron (org.). Século XXI: Qual conhecimento? Qual currículo? Petrópolis: Vozes, 1999.

FELIPE, Jane. Erotização dos corpos infantis. In: LOURO, Guacira Lopes; FELIPE, Jane GOELLNER, Silvana Vilodre (org.). Corpo, gênero e sexualidade: um debate contemporâneo na educação. 2. ed Petrópolis: Vozes, 2005. p. 53-65.

. Infância, gênero e sexualidade. Educação e realidade 25(1):115131, jan./jun. 2000.

FELIPE, Jane e GUIZZO, Bianca Salazar. Erotização dos corpos infantis na sociedade de consumo. Pro-posições. Campinas, v. 14, n.3(42), set./ dez. 2003, p. 119-132.

FISCHER, Rosa. Identidade, cultura e mídia: a complexidade de novas questões educacionais na contemporaneidade. In: SILVA, Luiz Heron (Org.). Século XXI: qual conhecimento? Qual currículo? Petrópolis: Vozes, 1999, p. 18-32.

. Televisão e educação: fruir e pensar a TV. Belo Horizonte: Autêntica, 2001.

FORNA, Aminatta. Mãe de todos os mitos: com a sociedade modela e reprime as mães. Rio de Janeiro: Ediouro, 1999.

FOUCAULT, Michel. História da Sexualidade 1. A vontade de saber. Rio de Janeiro: Graal, 1993.

. Microfísica do poder. Rio de Janeiro: Graal, 1992.

. Vigiar e punir. Petrópolis: Vozes, 1989. 
GREEN, Jonathan. Amor de mãe. In: Revista Grande Reportagem, n. 126, set/2001, p. 76-84.

GUERRA, Judite. Dos “segredos sagrados”: gênero e sexualidade no cotidiano de uma escola infantil. Dissertação. PPGEDU/FACED/UFRGS, Porto Alegre, 2005.

GUIZZO, Bianca S. Identidades de gênero e propagandas televisivas: um estudo no contexto da educação infantil. Dissertação. PPGEDU/ UFRGS, Porto Alegre, 2005.

HALL, Stuart. Identidades culturais na pós-modernidade. Trad. Tomaz Tadeu da Silva, Guacira Lopes Louro. Rio de Janeiro: DP\&A, 1997.

LOURO, Guacira Lopes. Gênero, sexualidade e educação. Petrópolis: Vozes, 1997.

(org.). 0 corpo educado: pedagogias da sexualidade. Belo Horizonte: Autêntica, 1999.

Um corpo estranho - ensaios sobre sexualidade e teoria queer. Belo Horizonte: Autêntica, 2004.

MEYER, Dagmar. As mamas como constituintes da maternidade: uma história do passado? Educação e Realidade. Porto Alegre: FACED/ UFRGS, v. 25, n. 2, jul./dez. 2000, p. 117-134.

MEYER, Dagmar. Educação, saúde e modos de inscrever uma forma de maternidade nos corpos femininos. Revista Movimento, POA/RS, v. 9, n. 3, p. 38-52, 2003.

. Gênero e Educação: teoria e política. In: LOURO, Guacira; $\overline{\text { FELIPE}}$, Jane; GOELLNER, Silvana (Orgs.) Corpo, gênero e sexualidade: um debate contemporâneo na Educação. Petrópolis: Vozes, 2003 p. 9-27. 
PEREIRA, Rita Marisa Ribes. Infância, televisão e publicidade: uma metodologia de pesquisa em construção. Cadernos de Pesquisa, São Paulo, n. 116, p. 81-105, jul. 2002.

ROSA, Graciema da. O corpo feito cenário. In: MEYER, Dagmar; SOARES, Rosângela (org.). Corpo, gênero e sexualidade. Porto Alegre: Mediação, 2004. p. 17-30.

. Gênero e sexualidade para consumo. In: LOURO, Guacira; FELIPE, Jane; Goellner, Silvana (Orgs.) Corpo, gênero e sexualidade: um debate contemporâneo na Educação. Petrópolis: Vozes, 2003 p. 149-159

SCOTT, J. Gênero: uma categoria útil de análise histórica. Educação \& Realidade, n. 20(2):71-100, 1995.

STEINBERG, Shirley. Kindercultura: a construção da infância pelas grandes corporações. In: SILVA, L. H. et al. (org.). Identidade social e a construção do conhecimento. Porto Alegre: PMPA, 1997. p. 98-145.

STEINBERG, Shirley; KINCHELOE, Joe. (org.). Culttura infantil: a construção corporativa da infância. Rio de Janeiro: Civilização Brasileira, 2001.

UNESCO. Inocência em perigo: abuso sexual de crianças, pornografia infantil e pedofilia na internet. Unesco, Garamond, 1999.

VEIGA, Aida. Infância Hi-Tec. Revista Época, p. 70-84, 3/setembro/2003.

WALKERDINE, Valerie. A cultura popular e a erotização das garotinhas. Educação \& Realidade, 24(2):75-88, jul./dez. 1999.

WEEKS, Jeffrey. O corpo e a sexualidade. In: LOURO, Guacira (org.). O corpo educado: pedagogias da sexualidade. Belo Horizonte; Autêntica, 1999. . 35-82. 
